\title{
Rancang Bangun Sistem Detector Tiket Kereta Api Menggunakan RFID Berbasis Mikrokontroller
}

\author{
Roza Susanti ${ }^{1}$, Albar $^{2 *}$, Ifni Joi ${ }^{3}$, Agung Fitratana ${ }^{4}$ \\ ${ }^{1234}$ Jurusan Teknik Elektro Politeknik Negeri Padang \\ rozasusanti@pnp.ac.id \\ Kampus Politeknik Negeri Padang, Limau Manis Padang
}

\begin{abstract}
The design of a prototype train ticket detector system using RFID-based microcontrollers has been made for replacing manual methods that still require officers to check tickets. This tool becomes a useful thing for a passenger to make easier going into the train departure room. The system made consists of 2 RFID units, 2 servo motors as an entrance and exit bar, an LCD circuit, and also facilitated with a buzzer circuit. This tool works when the RFID card is pasted to the RFID reader and the Arduino Uno Microcontroller will process the data whether the RFID card contains a balance and is sufficient to purchase train tickets. Then if the balance is sufficient, then the entrance gate bar is initially closed, it will open and the prospective passenger will enter the waiting room. However, If the balance is insufficient, the portal remains closed and the buzzer will be active and the balance will be displayed on the LCD. Furthermore, by pasting the RFID card on the exit portal crossbar to the RFID reader so the portal on the exit will open.
\end{abstract}

Keywords: portal crossbar, RFID, Arduino Uno Microcontroller, Servo Motor, Buzzer, LCD.

\begin{abstract}
Abstrak - Telah dibuat rancang bangun sistem detector tiket kereta api menggunakan RFID berbasis mikrokontroller menggantikan cara manual yang selama ini masih memerlukan petugas untuk melakukan pengecekan tiket. Alat ini bermanfaat untuk mempermudah saat akan masuk kedalam ruang tunggu keberangkatan kereta api. Sistem yang dibuat terdiri atas 2 buah RFID, 2 buah motor servo sebagai palang pintu masuk dan keluar, rangkaian LCD, dan rangkaian buzzer. Alat ini bekerja pada saat RFID tag di tempelkan pada RFID reader dan Mikrokontroller Arduino Uno mengolah data apakah kartu RFID tag berisi saldo dan mencukupi pembelian tiket kereta. Kemudian jika saldo mencukupi, maka palang portal pintu masuk pada kondisi awalnya tertutup maka akan terbuka dan calon penumpang akan masuk kedalam ruang tunggu. Jika saldo tidak mencukupi, maka portal tetap tertutup dan buzzer akan aktif. Jumlah saldo akan ditampilkan pada LCD. Pada palang portal pintu keluar, cukup dengan menempelkan RFID tag ke RFID reader maka portal pada pintu keluar akan terbuka.
\end{abstract}

Kata kunci: Palang portal, RFID, Mikrokontroler Arduino Uno, Motor Servo, Buzzer, LCD

(C) 2018 Elektron Jurnal Ilmiah

\section{PENDAHULUAN}

Transportasi adalah salah satu aspek kebutuhan yang penting dalam kehidupan masyarakat. Hampir seluruh aktifitas sehari-hari membutuhkan layanan jasa transportasi seperti dalam hal pekerjaan, pendidikan dan hal penting lainnya. Kota Padang yang merupakan pusat perekonomian dan pemerintahan memiliki aksesibilitas layanan transportasi yang cukup banyak, seperti : bus, travel, pesawat terbang, kapal laut, kereta api dan jasa transportasi lainnya. Hal tersebut memudahkan masyarakat untuk memilih layanan transportasi yang ingin digunakan sebagai sarana penunjang dalam aktifitas sehari-hari. Salah satu layanan transportasi yang tersedia di Kota Padang menuju Kota Pariaman adalah kereta api Sibinuang yang dikelola oleh PT. KAI Divisi Regional II.

Faktor yang mempengaruhi masyarakat Kota Padang dan Kota Pariaman menggunakan kereta api adalah muatan/jumlah penumpang yang banyak, lebih tepat waktu, dan harga yang terjangkau bagi semua kalangan masyarakat. Berdasarkan data dari Badan Pusat Statistik, mencatat jumlah penumpang kereta api Sibinuang setiap tahunnya mengalami peningkatan. Pada tahun 2016 jumlah penumpang yang tercatat menggunakan kereta api Sibinuang sebanyak 1.018.200 atau meningkat $5.45 \%$ dan diakhir tahun 2017 tercatat 1.036.277 atau meningkat $1.7 \%$ dari tahun sebelumnya. Peningkatan jumlah penumpang yang terus berlanjut setiap tahunnya sangat diperlukan pelayanan serta fasilitas yang mendukung dan memadai. Pada kereta api Sibinuang, pelayanan pembelian tiket berupa tiket thermal, yaitu tiket yang berbentuk seperti struk belanja di supermarket. Proses pemeriksaan tiket dilakukan secara manual oleh petugas kereta api. Pemeriksaan tiket secara manual ini kurang kondusif dan efisien pada saat jam sibuk, harihari besar seperti lebaran atau libur nasional, hal ini dikarenakan antrian yang panjang untuk pemeriksaan tiket calon penumpang. Sebelumnya pengembangan 
teknologi untuk pelayanan pembelian tiket dibuat oleh [1] dengan judul Sistem Pembelian Tiket Kereta Api Menggunakan Barcode Berbasis Mikrokontroler AT89s51. Pada pengembangan ini hanya terbatas pada pembelian tiket saja, sehingga penulis mengembangkan suatu sistem dimana pembelian dan pengecekan tiket kereta api dilakukan secara otomatis tanpa harus dilakukan oleh petugas kereta api

\section{METODE PENELITIAN}

Secara keseluruhan alat ini tersusun atas dua bagian penting yang saling berhubungan satu sama lain yaitu hardware dan software. Kedua bagian ini harus saling sinkron satu sama lain agar maksud dan tujuan dari pembuatan alat ini tercapai dan sesuai dengan yang diharapkan. Bagian hardware terdiri dari perancangan rangkaian elektronika dari rangkaian RFID, rangkaian LCD, rangkaian motor servo, rangkaian buzzer dan perancangan mekanik secara keseluruhan. Bagian software terdiri dari flowchart dan program.

\section{A.Rancang Bangun Sistem Secara Keseluruhan}

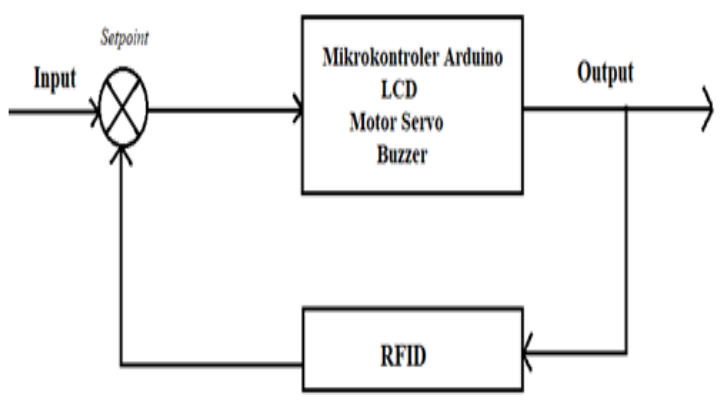

Gambar 1. Blok Diagram Sistem Pintu Masuk Stasiun

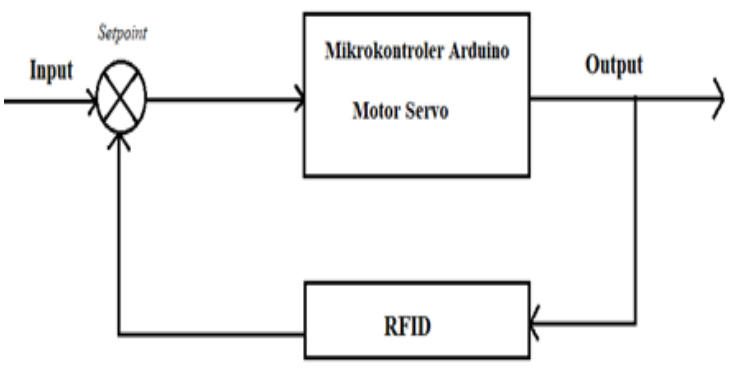

Gambar 2. Blok Diagram Sistem Pintu Keluar Stasiun

Input dari rangkaian ini yaitu menggunakan 2 buah RFID. RFIDyang pertama digunakan untuk pembelian tiket kereta dan membuka pintu masuk menggunakan motor servo yang pertama dan RFIDyang kedua digunakan untuk membuka pintu keluar menggunakan motor servo yang kedua. RFID menggunakan sistem identifikasi dengan gelombang radio, karena itu minimal dibutuhkan dua buah perangkat agar alat ini dapat berfungsi, adapun perangkat yang dibutuhkan disebut tag untuk mengirimkan data dari piranti portable dan reader untuk membaca, kemudian diproses oleh mikrokontroller Arduino Uno. Hasil dari pembacaan RFID akan di tampilkan pada LCD. Jika saldo tidak mencukupi maka buzzer akan berbunyi.

\section{B. Perancangan Perangkat Keras (Hardware)}

Perancangan dan pembuatan perangkat. keras ini merupakan perancangan skema atau rangkaian elektronik pada alat sehingga dapat membaca RFID pada alat.

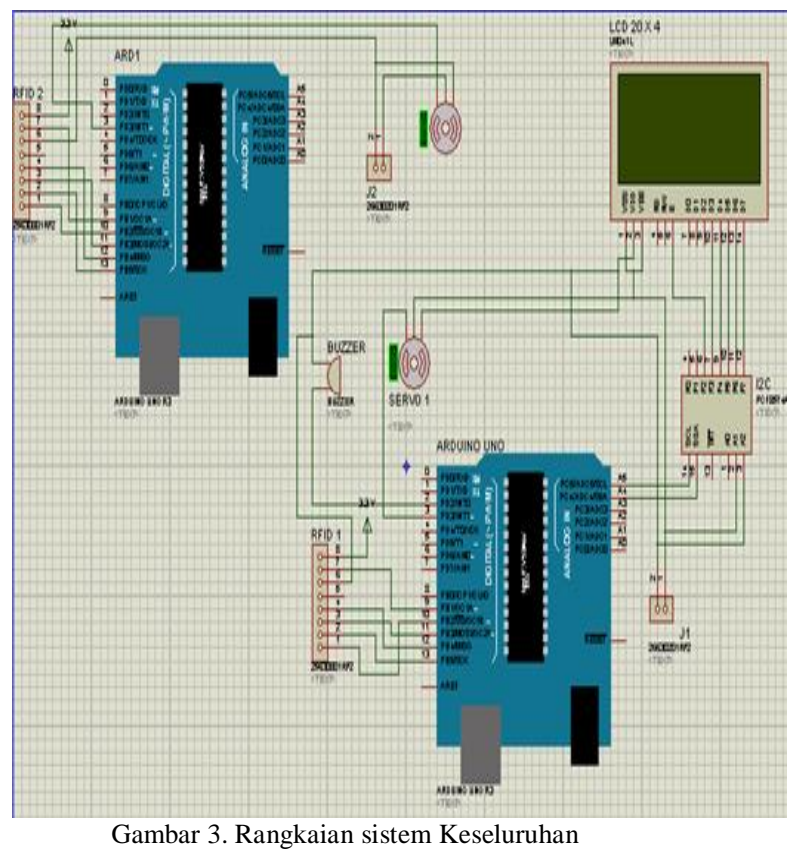

Rangkaian ini merupakan gambaran dari sistem detektor tiket kereta api, dimana Arduino Uno sebagai otak dari sistem secara keseluruhan . Sistem ini bekerja pada tegangan 5V DC dan 9V DC dengan sumber tegangan dari power supply. Pada rangkaian ini, RFID yang pertama digunakan untuk pembelian tiket kereta sedangkan RFID yang kedua digunakan untuk membuka pintu keluar stasiun. Data dari kedua RFID tersebut diolah oleh Arduino Uno dan kemudian akan ditampilkan pada LCD, jika saldo tidak mencukupi pembelian tiket maka buzzer akan aktif.

\section{C.Perancangan Perangkat Lunak}

Perancangan perangkat lunak merupakan perancangan mengenai algoritma pemograman yang akan digunakan pada sistem. Algoritma merupakan garis besar jalannya suatu program. Salah satu bentuk algoritma dituangkan dalam bentuk diagram alir ( flowchart). Adapun bentuk flowchart yang akan dirancang terdiri dari dua bagian yaitu :

1. Akses pintu masuk stasiun

2. Akses pintu keluar stasiun

\section{Algoritma}

1. Menginisialisasi pin $\mathrm{I} / \mathrm{O}$ yang digunakan, yaitu Modul RFID, Motor Servo, LCD, Buzzer. 
2. Jika jumlah saldo besar dari Rp.5000 maka servo akan membuka portal pintu masuk.

3. Jika jumlah saldo kecil dari Rp.5000 maka portal pintu tetap tertutup dan buzzer akan berbunyi.

\section{E.Flowchart Akses Pintu Masuk Stasiun}

Prinsip kerja akses pintu masuk stasiun dengan inisialisasi input yaitu RFID dan output motor servo, LCD dan buzzer. RFID reader akan mendeteksi saldo pada RFID tag. Jika saldo besar dari Rp.5000 maka motor servo yang ada pada pintu masuk akan terbuka 900. Jika saldo kurang dari Rp.5000 maka servo akan tetap tertutup dan buzzer aktif.

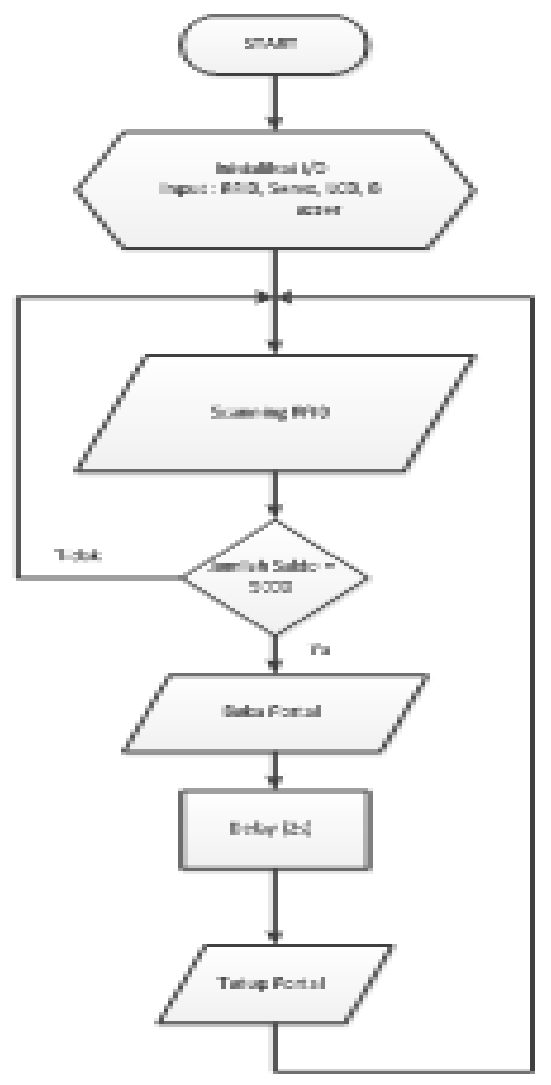

Gambar 4. Flowchart pintu masuk stasiun

\section{F. Flowchart Akses Pintu Masuk Stasiun}

Prinsip kerja akses pintu keluar stasiun dengan inisialisasi input yaitu RFID dan output motor servo. Pada akses pintu keluar tidak menggunakan saldo untuk membuka portal pintu keluar. Pintu akan terbuka setelah RFID tag di taping pada RFID reader.

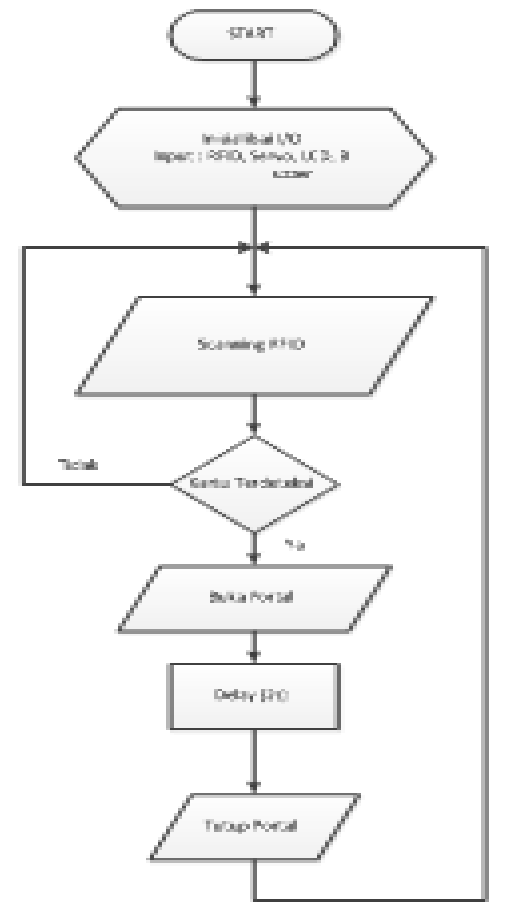

Gambar 5. Flowchart Pintu Keluar Stasiun

\section{HASIL DAN PEMBAHASAN}

Pengujian dan analisa alat bertujuan untuk mengetahui apakah alat yang telah dibuat sesuai dengan apa yang telah direncanakan sebelumnya, hal tersebut dapat dilihat dari hasil-hasil yang diperoleh pada pengujian alat. Pengujian dilakukan berdasarkan pada blok diagram.Berikut langkah-langkah dan pokok pembahasan yang akan di lakukan dalam pengujian diantaranya.

1. RFID

2. Motor Servo

\section{A.Pengujian dan Analisa RFID RC522}

Cara pengujian RFID yaitu:

1. Menghubungkan supply tegangan pada pin SDA dan Ground pada RFID

2. Mengaktifkan rangkaian mikrokontroller yang telah terprogram untuk menguji RFID

3. Mengukur jarak deteksi RFID tag dengan RFID reader.

4. Mengukur gelombang dan Frekuensi pada pin SDA.

Modul RFID RC522 digunakan pada akses pintu keluar dan masuk stasiun. Pada RFID proses identifikasi dilakukan oleh RFID tag dan RFID reader, yang telah diprogram pada mikrokontroler arduino Uno R3 berupa data angka identifikasi (ID number) yang unik untuk setiap RFID tag yang digunakan, sehingga tidak ada RFID tag yang memiliki ID number yang sama. RFID reader merupakan penghubung antara 
software aplikasi dengan antena yang akan memancarkan gelombang radio ke RFID tag. Gelombang radio yang ditransmisikan oleh antena berpropagasi pada ruangan disekitarnya. Akibatnya dapat berpindah secara wireless ke tag RFID yang berada berdekatan dengan antena. RFID Reader selain mempunyai penerima internal gelombang RF yang berfungsi menangkap gelombang elektromagnetik, juga mempunyai fungsi khusus untuk menangkap datadata analog dari gelombang RF yang dipancarkan oleh RFID Tag Card dan mengubahnya menjadi data-data digital. Berikut hasil pengujian tag RFID berupa ID card pada akses RFID pintu masuk dan keluar Stasiun yang ditempelkan pada RFID reader dengan jarak yang telah ditentukan adalah sebagai berikut:

Tabel 1. Hasil pengujian jangkauan jarak kartu RFID

\begin{tabular}{cccccc}
\hline $\begin{array}{c}\text { Akses pintu } \\
\text { Stasiun }\end{array}$ & \multicolumn{5}{c}{ Jarak pembacaan kartu } \\
\cline { 2 - 5 } & $1 \mathrm{~cm}$ & $2 \mathrm{~cm}$ & $3 \mathrm{~cm}$ & $4 \mathrm{~cm}$ & $5 \mathrm{~cm}$ \\
& & & & & \\
\hline RFID akses & Terb & Terba & Terb & Tidak & Tidak \\
pintu masuk & aca & ca & aca & terbaca & terbaca \\
\hline RFID akses & Terb & Terba & Terb & Tidak & Tidak \\
pintu keluar & aca & ca & aca & terbaca & terbaca \\
\hline
\end{tabular}

Dari tabel 1 diatas dapat dilihat bahwa hasil pengujian pada RFID tag berupa ID card dengan RFID reader untuk akses pintu masuk maupun keluar area stasiun hanya dapat mengakses jarak maksimal $3 \mathrm{~cm}$ sesuai dengan karakteristik RFID RC522.

\section{B.Pengujian dan Analisa Motor Servo}

Tujuan dari pengujian analisa pada motor servo adalah untuk menentukan kondisi motor servo saat berputar dalam hitungan derajat setelah diberikan output dari mikrokontroller arduino.Cara pengujian Motor servo yaitu:

1. Setelah program selesai dibuat maka download program tersebut kedalam mikrokontroler arduino menggunakan kabel downloader.

2. Memberikan sumber 9V DC pada mikrokontroler kemudian melakukan pengukuran pada pin 3 arduino uno.

\begin{tabular}{cccc}
\multicolumn{4}{c}{ Tabel 2. Pengujian Motor Servo } \\
\hline \multirow{2}{*}{ Keadaan } & $\begin{array}{l}\text { Sudut } \\
\text { Servo }\end{array}$ & Lebar Pulsa & Arah Putaran \\
& $0^{0}$ & $0,5 \mathrm{~ms}$ & - \\
\hline Awal & $90^{0}$ & $1,5 \mathrm{~ms}$ & $\mathrm{CW}$ \\
\hline Buka &
\end{tabular}

Sinyal PWM memiliki frekuensi gelombang yang tetap namun duty cycle bervariasi. Duty Cycle merupakan representasi dari kondisi logika high dalam suatu periode sinyal dan di nyatakan dalam bentuk (\%) dengan range $0 \%$ sampai $100 \%$. Dengan kata lain siklus kerja atau duty cycle adalah perbandingan lama kondisi ON dan kondisi OFF suatu sinyal pada suatu periode. Motor Servo bekerja pada sinyal digital dengan periode $20 \mathrm{~ms}$, dan range time high dan time low adalah 0,5 $2 \mathrm{~ms}$. Dari hasil pengujian pada saat diberikan pulsa dengan lebar $0,2 \mathrm{~ms}$ motor servo berada pada sudut 00 dan pada saat diberikan pulsa dengan lebar 0,6 ms motor servo berada pada sudut 900 . Motor servo ini nantinya dapat membuka dan menutup portal pintu masuk dan pintu keluar. Motor servo dapat berputar CW dan juga CCW dimana apabila motor servo berputar CW (Counter Wise) maka motor akan berputar searah jarum jam dan apabila motor servo berputar CCW (Counter Clock Wise) maka motor akan berputar berlawanan arah jarum jam. Pada saat motor servo berada pada posisi awal yaitu pada sudut 00 lebar pulsa yang dihasilkan adalah $0,2 \mathrm{~ms}$. Apabila keadaan motor servo $900 \mathrm{CW}$ ini menghasilkan lebar pulsa 0,6 ms.

\section{Analisa Keseluruhan}

Pada tahap awal untuk memasuki stasiun melalui akses portal masuk digunakan RFID tag berupa ID card yang ditempelkan pada RFID reader sehingga mengaktifkan motor servo untuk portal pintu masuk atau pintu keluastasiun akan terbuka 900. RFID reader merupakan penghubung antara software aplikasi dengan antena yang akan memancarkan gelombang radio ke RFID tag. Gelombang radio yang ditransmisikan oleh antena berpropagasi pada ruangan disekitarnya. Akibatnya dapat berpindah secara wireless ke tag RFID yang berada berdekatan dengan antena. Setelah penempelan RFID tag pada RFID reader maka pada LCD akan tampil Sisa saldo dan pintu akan terbuka jika saldo pada RFID tag minimal Rp.5000. Berikut adalah tabel kondisi untuk pengujian alat sesuai jumlah saldo yang ada didalam RFID tag :

Tabel 3a. Pengujian alat berdasarkan jenis kartu

\begin{tabular}{|c|c|c|c|}
\hline $\begin{array}{l}\text { Jenis } \\
\text { Kartu }\end{array}$ & $\begin{array}{c}\text { Jumlah } \\
\text { Saldo }\end{array}$ & $\begin{array}{l}\text { Kondisi } \\
\text { Motor }\end{array}$ & Buzzer \\
\hline \multirow{2}{*}{ Platinum } & 150000 & Terbuka $90^{\circ}$ & Off \\
\hline & 0 & Tertutup & On \\
\hline \multirow{2}{*}{ Gold } & 100000 & Terbuka $90^{0}$ & Off \\
\hline & 0 & Tertutup & On \\
\hline \multirow{2}{*}{ Silver } & 50000 & Terbuka $90^{\circ}$ & Off \\
\hline & 0 & Tertutup & On \\
\hline \multicolumn{4}{|c|}{ Tabel 3b. Pengujian alat berdasarkan jenis kartu } \\
\hline \multirow{2}{*}{\multicolumn{2}{|c|}{ Tampilan LCD }} & Jumlah & Kondisi \\
\hline & & Saldo & Motor \\
\hline \multirow{2}{*}{\multicolumn{2}{|c|}{$\begin{array}{c}\text { SILAHKAN MASUK } \\
\text { SALDO ANDA }=145090 \\
\text { TERIMAKASIH }\end{array}$}} & 150000 & Terbuka $90^{\circ}$ \\
\hline & & & \\
\hline
\end{tabular}




\begin{tabular}{|c|c|c|}
\hline $\begin{array}{l}\text { MOHON MAFF } \\
\text { SALDO ANDA HABIS }\end{array}$ & 0 & Tertutup \\
\hline $\begin{array}{c}\text { SILAHKAN MASUK } \\
\text { SALDO ANDA }=95600 \\
\text { TERIMAKASIH }\end{array}$ & 100000 & Terbuka $90^{\circ}$ \\
\hline $\begin{array}{l}\text { MOHON MAPF } \\
\text { SALDO ANDA HABIS }\end{array}$ & 0 & Tertutup \\
\hline $\begin{array}{c}\text { SILAHKAN MASUK } \\
\text { SALDO ANDA }=45000 \\
\text { TERIMAKASIH }\end{array}$ & 50000 & Terbuka $90^{\circ}$ \\
\hline $\begin{array}{l}\text { MOHON MAPF } \\
\text { SALDO ANDA HABIS }\end{array}$ & 0 & Tertutup \\
\hline
\end{tabular}

Berdasarkan tabel di atas dapat dijelaskan bahwa jumlah saldo setiap kali taping akan berkurang sebanyak Rp.5000 dan pintu akan terbuka. Jika saldo Rp.0 maka buzzer akan aktif dan pintu tetap tertutup

\section{KESIMPULAN}

RFID Tag sebagai scanning kartu untuk registrasi tiket kereta api dengan 3 macam kartu yang digunakan yaitu Platinum dengan jumlah saldo Rp.150.000, Gold dengan jumlah saldo Rp.100.000, dan Silver dengan jumlah saldo Rp.50.000. Motor servo sebagai palang pintu masuk maupun keluar stasiun yang akan aktif jika saldo pada pada kartu RFID tag berjumlah minimal Rp.5000. LCD sebagai tampilan jumlah saldo penumpang kereta api. Setiap kali tapping maka tampilan pada LCD akan berkurang sebanyak Rp.5000 dari jumlah saldo awal. Jika saldo sudah habis maka tampilan pada LCD yaitu "MOHON MAAF SALDO ANDA HABIS. Buzzer sebagai alarm bagi calon penumpang kereta api jika saldo habis atau kecil dari Rp.5000. sehingga alat tidak terhubung dengan smartphone android.

\section{REFERENSI}

[1] Medilla Kusriyanto. Nendy Wiswono. Sistem Palang Pintu Perlintasan Kereta Api Otomatis Dengan Komunikasi Wireless Berbasis Arduino. Teknoin Vol. 23 No. 1 Maret 2017 : 73-80.

[2] M. Azzam Firdaus, Aryo Baskoro Utomo. Miniatur Palang Pintu Kereta Api Otomatis dengan Menampilkan Kecepatan Kereta Serta Waktu Tunggu Menggunakan Arduino.

[3] C Xian-gang, Z Jian-bin. Servo Motor Decoupling Control Based on PI Fuzzy Adaptive Method. TELKOMNIKA (Telecommunication Computing Electronics and Control). 2013; 11(5): 2612-1618.

[4] W Yeqin. Direct Drive Electrohydraulic Servo Control System Design with SelfTuning Fuzzy PID Controller. TELKOMNIKA (Telecommunication Computing Electronics and Control). 2013; 11(6): 3374-3382.

[5] X Xu, H Lin. Speed Loop Control Research of Roll Stable Servo Platform. TELKOMNIKA (Telecommunication Computing Electronics and Control). 2013; 11(8): 4512-4516.

[6] Musfirah Putri Lukman Husni Angriani. Implementasi Teknologi Rfid Pada Sistem Antrian Rekam Medis Pasien Di Rumah Sakit. ILKOM Jurnal Ilmiah Volume 10 Nomor 1 April 2018. Hal 105-112

[7] Susanti, Roza dan Budi Bakhtiar, "Pengaturan Portal Pada Pengurutan Parkir Mobil dengan Menggunakan RFID dan PC". Padang: Elektron Vol. 1 No. 2, 2009. 